\title{
Growth Plate Closed
}

National Cancer Institute

\section{Source}

National Cancer Institute. Growth Plate Closed. NCI Thesaurus. Code C139148.

A finding indicating that the epiphyseal plate is fully calcified. 